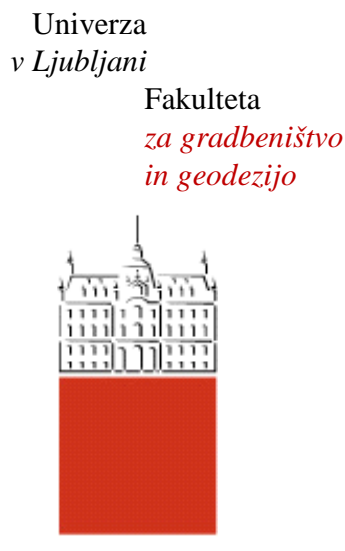

Jamova 2

1000 Ljubljana, Slovenija http://www3.fgg.uni-lj.si/

DRUGG - Digitalni repozitorij UL FGG http://drugg.fgg.uni-lj.si/

Ta članek je avtorjeva zadnja recenzirana različica, kot je bila sprejeta po opravljeni recenziji.

Prosimo, da se pri navajanju sklicujete na bibliografske podatke, kot je navedeno:

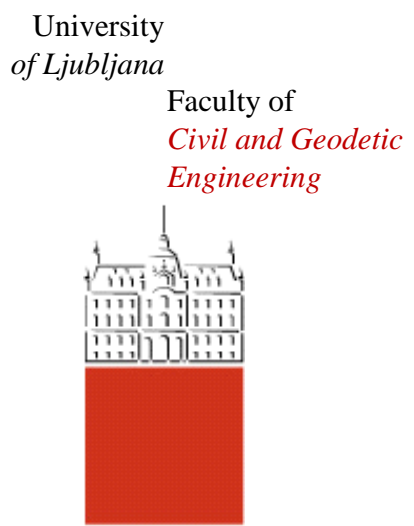

Jamova 2

SI - 1000 Ljubljana, Slovenia http://www3.fgg.uni-lj.si/en/

DRUGG - The Digital Repository http://drugg.fgg.uni-lj.si/

This version of the article is author's manuscript as accepted for publishing after the review process.

When citing, please refer to the publisher's bibliographic information as follows:

Schnabl, S., Planinc, I., Turk, G. in Srpčič, S. 2009. Fire analysis of timber composite beams with interlayer slip. Fire Safety Journal 44, 5: 770-778.

DOI: $10.1016 /$ j.firesaf.2009.03.007. 


\title{
Fire analysis of timber composite beams with interlayer slip
}

\author{
S. Schnabl, ${ }^{*}$ I. Planinc, G. Turk and S. Srpčič \\ University of Ljubljana, Faculty of Civil and Geodetic Engineering, Jamova 2, \\ SI-1115 Ljubljana, Slovenia
}

\begin{abstract}
The purpose of this paper is to model the behaviour of timber composite beams with interlayer slip, when simultaneously exposed to static loading and fire. A transient moisture-thermal state of a timber beam is analyzed by the Luikov equations, and mechanical behaviour of timber composite beam is modelled by Reissner's kinematic equations. The model can handle layers of different materials. Material properties are functions of temperature. The thermal model is validated against the experimental data presented in the literature. Generally, the model provides excellent agreement with the experimental data. It is shown that the material properties of timber play an important role in the fire resistance analysis of timber structures when exposed to fire.
\end{abstract}

Keywords: fire, charring, composites, slip, Reissner beam theory, finite difference method, finite element method.

\footnotetext{
*Corresponding author. Tel.: +38614768 615; Fax: +38614768629

E-mail address: sschnabl@fgg.uni-lj.si (S. Schnabl)
}

Preprint submitted to 


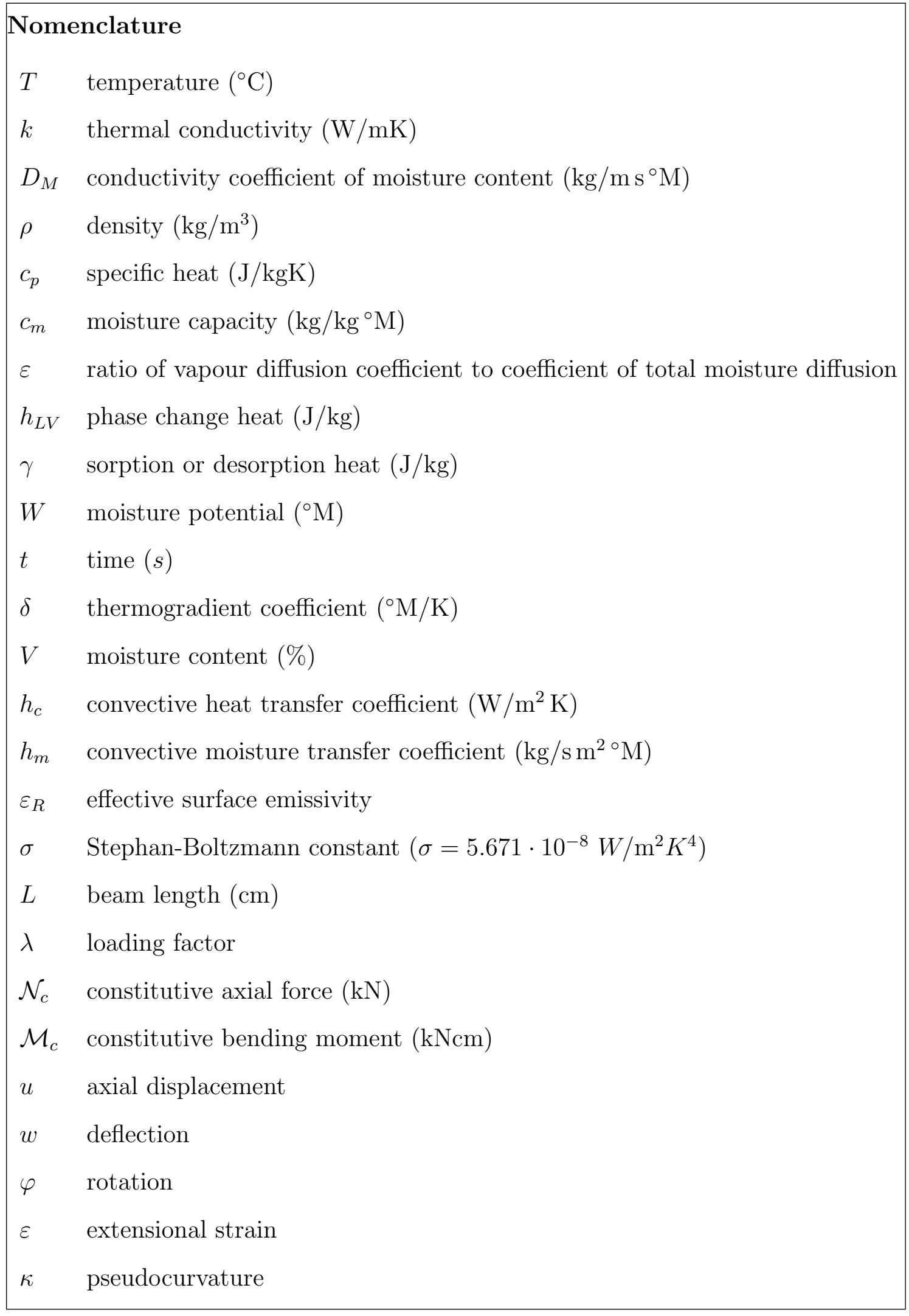




\begin{tabular}{|ll|}
\hline$N$ & number of collocation points \\
$\mathrm{N}_{\text {lay }}$ & number of layers \\
$\mathcal{R}_{1}, \mathcal{R}_{2}, \mathcal{M}$ & Euler-Lagrange multipliers \\
$\Delta$ & inter-layer slip $(\mathrm{cm})$ \\
$K$ & inter-layer slip modulus $\left(\mathrm{kN} / \mathrm{cm}^{2}\right)$ \\
$q_{t}$ & tangential contact traction $(\mathrm{kN} / \mathrm{cm})$ \\
$E$ & elastic modulus $\left(\mathrm{kN} / \mathrm{cm}^{2}\right)$ \\
$S$ & generalized boundary forces $(\mathrm{kN})$ \\
$p_{X}$ & uniformly distributed axial load $(\mathrm{kN} / \mathrm{cm})$ \\
$p_{Z}$ & uniformly distributed vertical load $(\mathrm{kN} / \mathrm{cm})$ \\
$m_{Y}$ & uniformly distributed bending moment $(\mathrm{kNcm} / \mathrm{cm})$ \\
Subscripts and superscripts & \\
$A$ & \\
c a & \\
\hline & ambient \\
& ith layer \\
& wood \\
\hline &
\end{tabular}

\section{Introduction}

Multi-layered structures have been playing an increasingly important role in different areas of engineering practice, perhaps most notably in civil, automotive, aerospace and aeronautic technology. With the limitation to civil engineering, classical cases of such structures are steel-concrete composite beams in buildings and bridges, wood-concrete floor systems, coupled shear walls, concrete beams externally reinforced with laminates, sandwich beams, and many more. It is well known, that the behaviour of these structures largely 
depends not only on different materials of individual components, but also by the type of their connection. One of the most quoted partial theory was developed by Newmark et al. [1] and was based on linear elastic theory. A number of linear analytical solutions were developed by several authors [2-7]. If material and geometric non-linearity is considered the numerical procedures need to be employed. Usually, displacement-based finite elements are introduced [8-11]. This paper is following a line of papers where strain-based finite elements are used [12-15]. There exist many ways how to obtain the connection between the components. Usually, mechanical shear connectors are employed to provide a desired composite action. With the use of rigid shear connectors, a full shear connection and full composite action between the individual components can be achieved. Consequently, conventional principles of the solid beam analysis can be employed. Unfortunately, the full shear connection can hardly be realized in practice and only an incomplete or partial interaction between the layers is usually obtained. As a result, an interlayer slip develops. With its sufficient magnitude, it significantly effects the mechanical behaviour of composite systems. Hence, the inclusion of the interlayer-slip effect into multi-layered beam theory is essential for optimal design and accurate/realistic representation of the actual mechanical response of multi-layered timber beams with partial interaction between the components when exposed to static loading and fire.

Ever since prehistoric times timber has been recognized as a very popular construction material. Nowadays, it has commonly been used in various fields of engineering. Due to its remarkable properties it has been used by many architects and designers of modern buildings. The capability to predict the behaviour of timber, particularly when exposed to fire, has become increas- 
ingly important in the field of fire safety engineering.

When numerically analyzing mechanical behaviour of load bearing timber beams in natural fires, the contributions of shrinkage-swelling, temperature, viscous creep and mechano-sorptive strains are of major importance. The development of all aforementioned strains is strongly affected by the actual temperature and moisture content distribution in the beams. Therefore, the determination of the spatial and temporal distribution of temperature and moisture content over the element is the first key phase of the analysis. When timber as a charring material is exposed to fire, it undergoes thermal degradation, i.e., pyrolysis. The pyrolysis of timber is a complex interplay of chemistry, heat, and mass transfer. It changes timber to char and gases (such as carbon dioxide and hydrocarbons), and consequently, modifies the density and other material characteristics. The process of thermal degradation starts when the temperature of timber reaches a certain threshold value which depends on the kind of timber, but is generally around $300^{\circ} \mathrm{C}$.

Because of the importance and complexity of the pyrolysis of timber, there is a substantial volume of work on the pyrolysis and charring of timber as a porous media [16-29]. Experimental observations of charring behaviour prove the mutual effect of temperature and moisture content gradients in timber, but it is rarely taken into consideration in the computational analysis of charring in fire situations. In this paper, a transient heat and moisture transfer over a timber beam exposed to standard fire conditions is considered. The governing equations of simultaneous heat and moisture transfer in porous media like timber were provided by Luikov [30].

Assuming a homogeneity of the temperature and moisture content field along 
the beam, the 2-D Luikov equations are solved for the cross-section of the timber beam. Furthermore, a symmetric cross-section, boundary and initial conditions are assumed. Due to a rectangular cross-section, a finite difference method is chosen for the solution of the hydro-thermal part of the problem. For the spatial integration the symmetric formulae based on quadratic shape functions are introduced, whereas for the time-integration linear shape functions are employed.

When the symmetric distribution of temperature and moisture content over the cross-section is known for each time step of the analysis, it can be used in the second key phase of the analysis, i.e. the analysis of the mechanical response of timber composite beams when exposed to static loading and fire. The effect of non-homogenous temperature and moisture distributions over the cross-section is taken into account by the integration of stresses induced by temperature and moisture content gradients. Each layer of a timber composite beam is modelled by linearized Reissner's [31] kinematic equations. Further, we assume that the transverse separation between the layers does not occur. The mathematical model of the timber composite beam is described by a set of algebraic-differential equations and boundary conditions which was solved by finite element method. The principle of virtual work has been employed as a basis for the finite element discretization. Thus, a modified form of the principle of virtual work by including the linear kinematic equations as constraining equations through Lagrangian multipliers is proposed. In this way, the displacement field vector is eliminated from the principle of virtual work. As a result, a deformation field vector remains the only unknown function to be approximated in the finite element implementation of the principle. This means that only extensional strains and pseudocurvatures of reference axis 
of individual layers and transverse shear deformations of layer cross-sections need to be interpolated. Furthermore, the present approach uses the concept of consistent equilibrium of constitutive and equilibrium-based stress-resultants [32] and the Galerkin type of the finite element formulation is employed [33]. With the use of the derived model for the analysis of the behaviour of composite timber beams exposed to fire, various parametric studies have been performed. The main emphasis has been devoted to the investigation of different parameters on vertical deflections of composite timber beams when exposed to standard fire conditions.

\section{Governing equations}

Heat and mass transfer in porous media is governed by two second order nonlinear partial differential equations (1)-(2) presented by Luikov [30]. The first equation describes heat conduction governed predominantly by temperature gradient but affected also by the effect of phase-change and heat on sorption and desorption, which depend on the moisture changes. The second equation describes moisture diffusion governed predominantly by moisture potential but is also considerably affected by temperature gradients. Furthermore, anisotropy and temperature and moisture content dependent material properties are assumed. The equations can be written as:

$$
\begin{gathered}
\rho c_{p} \frac{\partial T}{\partial t}-\rho c_{m}\left(\varepsilon h_{L V}+\gamma\right) \frac{\partial W}{\partial t}=\frac{\partial}{\partial y}\left(k_{y} \frac{\partial T}{\partial y}\right)+\frac{\partial}{\partial z}\left(k_{z} \frac{\partial T}{\partial z}\right), \\
\rho c_{m} \frac{\partial W}{\partial t}=\frac{\partial}{\partial y}\left(D_{M y}\left(\frac{\partial W}{\partial y}+\delta_{y} \frac{\partial T}{\partial y}\right)\right)+\frac{\partial}{\partial z}\left(D_{M z}\left(\frac{\partial W}{\partial z}+\delta_{z} \frac{\partial T}{\partial z}\right)\right) .
\end{gathered}
$$

In Eqs. (1)-(2) $k_{y}, k_{z}$ represent thermal conductivity $(\mathrm{W} / \mathrm{mK})$ in the crosssection of the beam. Similarly, $D_{M y}$ and $D_{M z}$ represent conductivity coeffi- 
cients of moisture content $\left(\mathrm{kg} / \mathrm{ms} \mathrm{s}^{\circ} \mathrm{M}\right), \rho$ represents density $\left(\mathrm{kg} / \mathrm{m}^{3}\right), c_{p}$ specific heat $(\mathrm{J} / \mathrm{kgK}), T$ temperature $\left({ }^{\circ} \mathrm{C}\right), c_{m}$ moisture capacity $\left(\mathrm{kg} / \mathrm{kg}{ }^{\circ} \mathrm{M}\right), \varepsilon$ ratio of vapour diffusion coefficient to coefficient of total moisture diffusion, $h_{L V}$ phase change heat $(\mathrm{J} / \mathrm{kg}), \gamma$ sorption or desorption heat $(\mathrm{J} / \mathrm{kg}), W$ moisture potential $\left({ }^{\circ} \mathrm{M}\right), t$ is time $(s)$ and $\delta_{y}, \delta_{z}$ are thermogradient coefficients $\left({ }^{\circ} \mathrm{M} / \mathrm{K}\right)$ in two orthogonal directions $y$ and $z$, respectively.

Moisture potential, $W$, is related to moisture content, $V$, by the linear relation

$$
V=c_{m} W
$$

A particular solution of the system of governing differential equations (1)(2) has to satisfy the initial and boundary conditions. The initial conditions prescribe the temperature and moisture potential of the cross-section of the beam at the initial time $t=0$ :

$$
T(y, z, 0)=T_{0}(y, z)
$$

and

$$
W(y, z, 0)=W_{0}(y, z) .
$$

The boundary conditions prescribe a heat and moisture flow on the exposed boundaries of the beam. It is assumed, that the flow magnitudes depend on differences between temperature and moisture potentials on the boundary and in the surrounding air. In the heat boundary condition the effect of evaporation on the heat flow is added, while in the moisture boundary condition the effect of temperature gradient is taken into account. Thus, the boundary conditions at the exposed surface are given by balancing heat conduction and moisture transfer at the surface with the radiative and convective heat and convective 
moisture input. The boundary conditions can be written as $-k_{y} \frac{\partial T}{\partial y} e_{n y}-k_{z} \frac{\partial T}{\partial z} e_{n z}=h_{c}\left(T-T_{A}\right)+\varepsilon_{R} \sigma\left(T^{4}-T_{A}^{4}\right)+(1-\varepsilon) h_{L V} h_{m}\left(W-W_{A}\right)$,

and

$D_{M y} \frac{\partial W}{\partial y} e_{n y}+D_{M z} \frac{\partial W}{\partial z} e_{n z}+D_{M y} \delta_{y} \frac{\partial T}{\partial y} e_{n y}+D_{M z} \delta_{z} \frac{\partial T}{\partial z} e_{n z}=-h_{m}\left(W-W_{A}\right)$

where $e_{n y}$ and $e_{n z}$ are the components of the unit normal to the boundary surface, $h_{c}$ and $h_{m}$ are convective heat transfer coefficient $\left(\mathrm{W} / \mathrm{m}^{2} \mathrm{~K}\right)$ and convective moisture transfer coefficient $\left(\mathrm{kg} / \mathrm{s} \mathrm{m}^{2}{ }^{\circ} \mathrm{M}\right)$, respectively. $T_{A}$ is the temperature, and $w_{A}$ is the moisture potential of the ambient. The second term in the right-hand side of Eq. (6) represents the radiative heat input, where $\varepsilon_{R}$ is the effective surface emissivity and, $\sigma$, is the Stephan-Boltzmann constant for radiation, $\left(\sigma=5.671 \cdot 10^{-8} \mathrm{~W} / \mathrm{m}^{2} K^{4}\right)$.

Composite beams are usually composed of various layers with different material characteristics. In addition to the boundary conditions (6)-(7), the conditions at the contact between the layers have to be prescribed as follows:

$$
\begin{gathered}
T_{j}^{i}=T_{j}^{i+1}, \quad W_{j}^{i}=W_{j}^{i+1}, \\
k_{z, j}^{i} \frac{\partial T_{j}^{i}}{\partial z} e_{n z, j}^{i}=k_{z, j}^{i+1} \frac{\partial T_{j}^{i+1}}{\partial z} e_{n z, j}^{i+1}, \quad\left(i=j=1, \ldots, \mathrm{N}_{\text {lay }}-1\right) \\
D_{M z, j}^{i} \frac{\partial W_{j}^{i}}{\partial z} e_{n z, j}^{i}=D_{M z, j}^{i+1} \frac{\partial W_{j}^{i+1}}{\partial z} e_{n z, j}^{i+1},
\end{gathered}
$$

where $i$ marks the layer, and $j$ marks the contact between the layers $i$ and $i+1$. Therefore, $T_{j}^{i}$ presents the temperature of layer $i$ in the contact $j$.

The ambiental moisture potential, $W_{A}$, is obtained through sorption isotherms. The effects of stress state and history of sorption are neglected. The above sys- 
tem of Eqs. (1)-(7) is solved by using finite difference method and a computer program is written in Matlab environment.

The mechanical response of timber composite beams when subjected to static loading is described by the following Euler-Lagrange equations of the finite element of the planar multi-layer composite beam, (see, [15, 34]):

$$
\begin{aligned}
& f_{i n_{\varepsilon}}=\left.\left(\mathcal{N}_{c}^{i}-\mathcal{R}_{1}^{i}\right)\right|_{x=x_{n_{\varepsilon}}}=0, \quad n_{\varepsilon}=1, \ldots, N_{\varepsilon} \\
& f_{N_{\text {lay }} N_{\varepsilon}+n_{\kappa}}=\left.\left(\mathcal{M}_{c}-\mathcal{M}\right)\right|_{x=x_{n_{\kappa}}}=0, \quad n_{\kappa}=1, \ldots, N_{\kappa} ; \\
& f_{N_{\text {lay }} N_{\varepsilon}+N_{\kappa}+i}=u^{i}(L)-u^{i}(0)-\sum_{n=1}^{N_{\varepsilon}} P_{n_{\varepsilon}}^{*}(x) \varepsilon_{n}^{i}=0, \\
& f_{N_{\text {lay }}\left(N_{\varepsilon}+1\right)+N_{\kappa}+1}=w(L)-w(0)+\varphi(0) L+\sum_{n=1}^{N_{\kappa}} P_{n_{\kappa}}^{* *}(x) \kappa_{n}=0, \\
& f_{N_{\text {lay }}\left(N_{\varepsilon}+1\right)+N_{\kappa}+2}=\varphi(L)-\varphi(0)-\sum_{n=1}^{N_{\kappa}} P_{n_{\kappa}}^{*}(x) \kappa_{n}=0, \\
& f_{N_{\text {lay }}\left(N_{\varepsilon}+1\right)+N_{\kappa}+2+i}=S_{1}^{i}+\mathcal{R}_{1}^{i}(0)=0, \\
& f_{N_{\text {lay }}\left(N_{\varepsilon}+2\right)+N_{\kappa}+3}=S_{2}+\mathcal{R}_{2}(0)=0, \\
& f_{N_{\text {lay }}\left(N_{\varepsilon}+2\right)+N_{\kappa}+4}=S_{3}+\mathcal{M}(0)=0, \\
& f_{N_{\text {lay }}\left(N_{\varepsilon}+2\right)+N_{\kappa}+4+i}=S_{4}^{i}-\mathcal{R}_{1}^{i}(0)+\int_{0}^{L}\left(p_{X}^{i}+q_{t, j-1}-q_{t, j}\right) \mathrm{d} x=0, \\
& f_{N_{\text {lay }}\left(N_{\varepsilon}+3\right)+N_{\kappa}+5}=S_{5}-\mathcal{R}_{2}(0)+\sum_{i=1}^{N_{\text {lay }}} \int_{0}^{L} p_{Z}^{i} \mathrm{~d} x=0, \\
& f_{N_{\text {lay }}\left(N_{\varepsilon}+3\right)+N_{\kappa}+6}=S_{6}-\mathcal{M}(0)+\mathcal{R}_{2}(0) L- \\
& \sum_{i=1}^{N_{\text {lay }}}\left(\int_{0}^{L} \int_{0}^{x} p_{Z}^{i} \mathrm{~d} x-\int_{0}^{L}\left(m_{Y}^{i}-z_{j} q_{t, j}+z_{j-1} q_{t, j-1}\right)\right) \mathrm{d} x=0,
\end{aligned}
$$

where 


$$
\begin{gathered}
q_{t, j}=\mathcal{F}\left(\Delta_{j}^{i}\right)=K \Delta_{j}^{i}, \\
\Delta_{j}^{i}=u^{i}-u^{i+1}, \\
w=w^{i}=w^{i+1}, \\
\varphi=\varphi^{i}=\varphi^{i+1},
\end{gathered}
$$

and

$$
P_{n_{\kappa}}^{*}(x)=\int_{0}^{L} P_{n_{\kappa}}(\xi) \mathrm{d} \xi \quad \text { and } \quad P_{n_{\kappa}}^{* *}(x)=\int_{0}^{L}\left(\int_{0}^{\xi} P_{n_{\kappa}}(\xi) \mathrm{d} \xi\right) \mathrm{d} \xi
$$

Within each finite element, see Eqs. (11)-(21), an extensional strain $\varepsilon^{i}$, and a pseudocurvature $\kappa$ of the reference axes of layer $i$ are interpolated by Lagrangian polynomials. Additionally, it is assumed that the variations of strain functions are approximated by the Dirac $\delta$-function. Therefore, for the construction of the finite-element model of the multi-layer composite beam with an interlayer slip the Petrov-Galerkin collocation method is used [39]. Consequently, discrete values $\varepsilon_{n}^{i}$ and $\kappa_{n}$ represent nodal values of the interpolated functions. Furthermore, $\mathcal{R}_{1}^{i}, \mathcal{R}_{2}^{i}, \mathcal{M}$ represent Euler-Lagrange multipliers. $q_{t}$ denote the tangential interlayer contact tractions in the contact plane between the layers. $\mathcal{N}_{\mathrm{C}}^{i}$ and $\mathcal{M}_{\mathrm{C}}$ is a constitutive axial force of layer $i$ and a constitutive bending moment of a multi-layer beam, respectively. In the case of linear elastic material, the constitutive forces are assumed to be given by the linear relations with respect to $\varepsilon^{i}$ and $\kappa$, and therefore, take the following notation:

$$
\begin{gathered}
\mathcal{N}_{\mathrm{C}}^{i}=C_{11}^{i} \varepsilon^{i}+C_{12}^{i} \kappa, \\
\mathcal{M}_{\mathrm{C}}=\sum_{i=1}^{N_{\text {lay }}}\left(C_{21}^{i} \varepsilon^{i}+C_{22}^{i} \kappa\right),
\end{gathered}
$$


in which material and geometric constants are denoted by $C_{11}^{i}, C_{12}^{i}, \ldots, C_{22}^{i}$; e.g. $C_{22}^{i}=E^{i} J^{i}$, where $E^{i}$ is the elastic modulus of layer $i$, and $J^{i}$ is the moment of inertia of layer $i$ with respect to the interlayer contact line; In Eqs. (22), $K$ denotes the slip modulus at the interlayer surface.

For a given loading factor, $\lambda$, Eqs. (11)-(21) constitute a system of $N_{\text {lay }}\left(N_{\varepsilon}+\right.$ $3)+N_{\kappa}+6$ non-linear algebraic equations for the same number of unknowns. There are $N_{\text {lay }}\left(N_{\varepsilon}+1\right)+N_{\kappa}+2$ internal degrees of freedom $\varepsilon_{n}^{i}, \kappa_{n}, \mathcal{R}_{1}^{i}(0), \mathcal{R}_{2}(0)$, and $\mathcal{M}(0)$, and $2 N_{\text {lay }}+4$ external degrees of freedom, i.e., nodal displacement and rotations $u^{i}(0), w(0), \varphi(0), u^{i}(L), w(L)$, and $\varphi(L)$ of the finite element. Integrals in the Eqs. (11)-(21) are evaluated numerically with Gauss's or Lobatto's integrations. The internal degrees of freedom are eliminated from the global system by the procedure of static condensation at the element level. The condensed global tangent stiffness matrix and the condensed residual force vector of the structure are then assembled by a classical way. For the solution of the equations a standard method for solutions of a system of non-linear equations is employed. Note, for non-singular solution of the Eqs. (11)-(21), at least one longitudinal boundary displacement of an arbitrary layer has to be prescribed. Eqs. (11)-(21), when written for the structure need to be solved by an incremental-iterative way. The time interval $[0, t]$ is divided into time steps $\left[t^{s}, t^{s+1}\right]$. For each time step $s+1$ and a given loading factor, $\boldsymbol{\lambda}^{s+1}$, the unknown nodal displacements, $\boldsymbol{x}^{s+1}$ are determined by the solution of the following system of equations:

$$
\boldsymbol{G}\left(\boldsymbol{x}^{s+1}, \boldsymbol{\lambda}^{s+1}, T^{s+1}, W^{s+1}, t^{s+1}\right)=\mathbf{0} .
$$

Similarly, the above system of Eqs. (11)-(21) is solved by using finite element method and a computer program is written in Matlab environment. 


\section{$3 \quad$ Numerical examples}

Numerical examples will demonstrate the applicability of the present mathematical model to predict a thermomechanical behaviour of timber beams when exposed to static loading and fire. The mathematical model presented in the paper will be numerically evaluated through the analysis of two examples: (i) A one-dimensional charring of a solid timber beam; (ii) Fire resistance of a two-layer timber composite beam exposed simultaneously to static loading and fire.

\subsection{One-dimensional charring of a solid timber beam}

In order to compare the present mathematical model with the one-dimensional empirical charring models presented in the literature, a one-dimensional charring of timber beam made of spruce, with a thickness $d$, and exposed to the standard fire conditions [35], is considered.

Generally, charring behaviour of timber can either be described by the mass loss rate $(\mathrm{g} / \mathrm{s})$ or by the rate of advance of the formed char front from the original surface $(\mathrm{cm} / \mathrm{s})$. The latter definition has been more widely used because it enables a determination of an effective residual cross-section area commonly employed in timber design calculations. The rate of charring is a complex process which depends upon the interaction between pyrolysis of timber and the generation of heat, both of which are functions of a number of factors such as the species, density moisture content, permeability, and thermophysical properties. Since material properties at elevated temperatures are difficult to determine, constant material properties of timber and char are used. The 
data for this case is as follows:

$$
\begin{aligned}
& T_{0}=20^{\circ} \mathrm{C}, \quad w_{0}=13^{\circ} \mathrm{M}, W_{A}=4^{\circ} \mathrm{M}, \rho_{\mathrm{w}}=370 \mathrm{~kg} / \mathrm{m}^{3}, \rho_{\mathrm{c}}=110 \mathrm{~kg} / \mathrm{m}^{3}, \\
& k_{\mathrm{w}}=0.12 \mathrm{~W} /(\mathrm{m} \mathrm{K}), k_{\mathrm{c}}=0.15 \mathrm{~W} /(\mathrm{m} \mathrm{K}), D_{M}=2.2 \cdot 10^{-8} \mathrm{~kg} /\left(\mathrm{m} \mathrm{s}^{\circ} \mathrm{M}\right), \\
& h_{L V}=2500 \mathrm{~kJ} / \mathrm{kg}, \quad h_{\mathrm{c}}=22.5 \mathrm{~W} /\left(\mathrm{m}^{2} \mathrm{~K}\right), \quad \varepsilon=0,3, c_{p, \mathrm{w}}=1530 \mathrm{~J} /(\mathrm{kg} \mathrm{K}), \\
& c_{p, \mathrm{c}}=1050 \mathrm{~J} /(\mathrm{kg} \mathrm{K}) c_{m}=0.01 \mathrm{~kg} /\left(\mathrm{kg}^{\circ} \mathrm{M}\right), \quad \delta=2.0^{\circ} \mathrm{M} / \mathrm{K}, \\
& h_{m}=2.5 \cdot 10^{-6} \mathrm{~kg} /\left(\mathrm{m}^{2} \mathrm{~s}^{\circ} \mathrm{M}\right), \mathrm{d}=0.3 \mathrm{~m}, \quad \gamma=0 .
\end{aligned}
$$

The comparison of different charring models is presented in Fig. 1. 


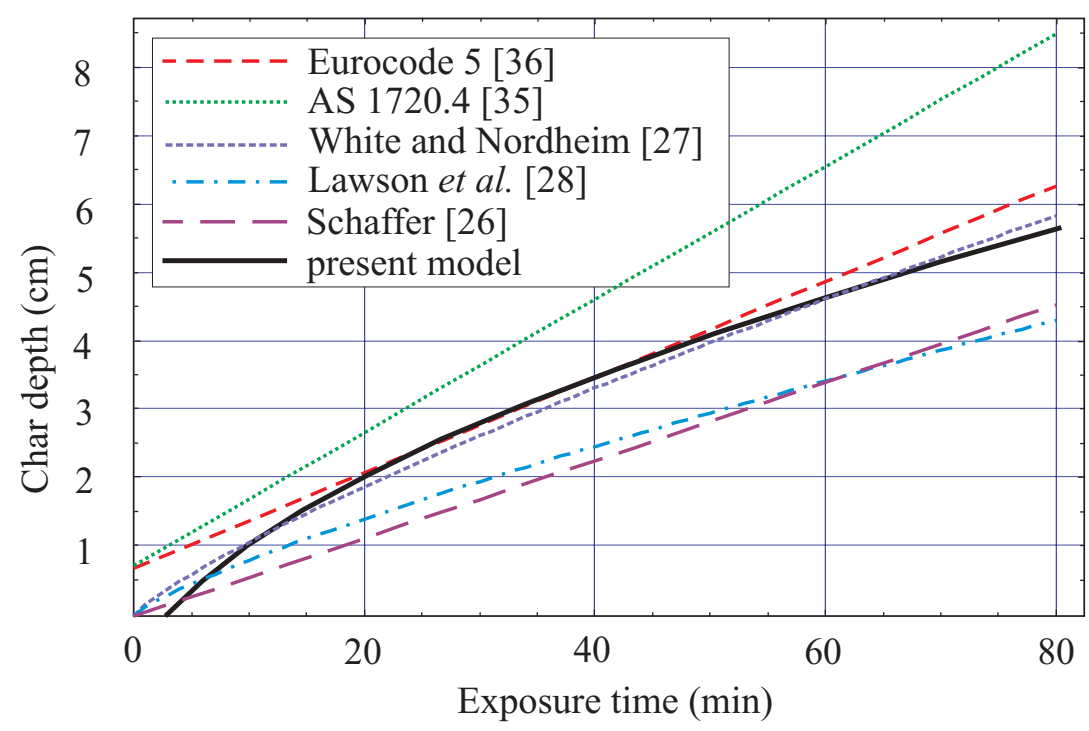

Figure 1. Comparison of different empirical charring models with the present one.

Most of the aforementioned models [27, 36, 37] suggest constant charring rates. The use of these charring rates is convenient but does not accurately reflect the actual charring behaviour of timber. To account for the char non-linearity, nonlinear charring models are developed, i.e., White and Nordheim [28], Lawson et al. [29].

Fig. 1 shows that models proposed in [36] and by Schaffer [27] differ considerably. The Lawson's and Schaffer's models differ slightly at the beginning, but are virtually equal at 60 minutes. Similarly, the model proposed by Eurocode 5 [37], White's and Nordheim's model [28], and the charring model proposed in this paper, differ considerably in the first 15 minutes, but later show similar results. All models described above are relatively simple to use. However, all empirical models are limited to one-dimensional cases. In all empirical models it is assumed also that charring of timber starts instantaneously after the exposure to fire. In reality, this is not the case. In our model, charring starts when the temperature of timber reaches the temperature of pyrolysis, which is around $300^{\circ} \mathrm{C}$. In this case, this happens nearly 4 minutes after the fire starts. 
Furthermore, to validate the proposed mathematical model for a thermomechanical analysis of timber beams when exposed to fire, numerical results are compared to the experimental results published by Fredlund [16, 17], see Fig. 2 .

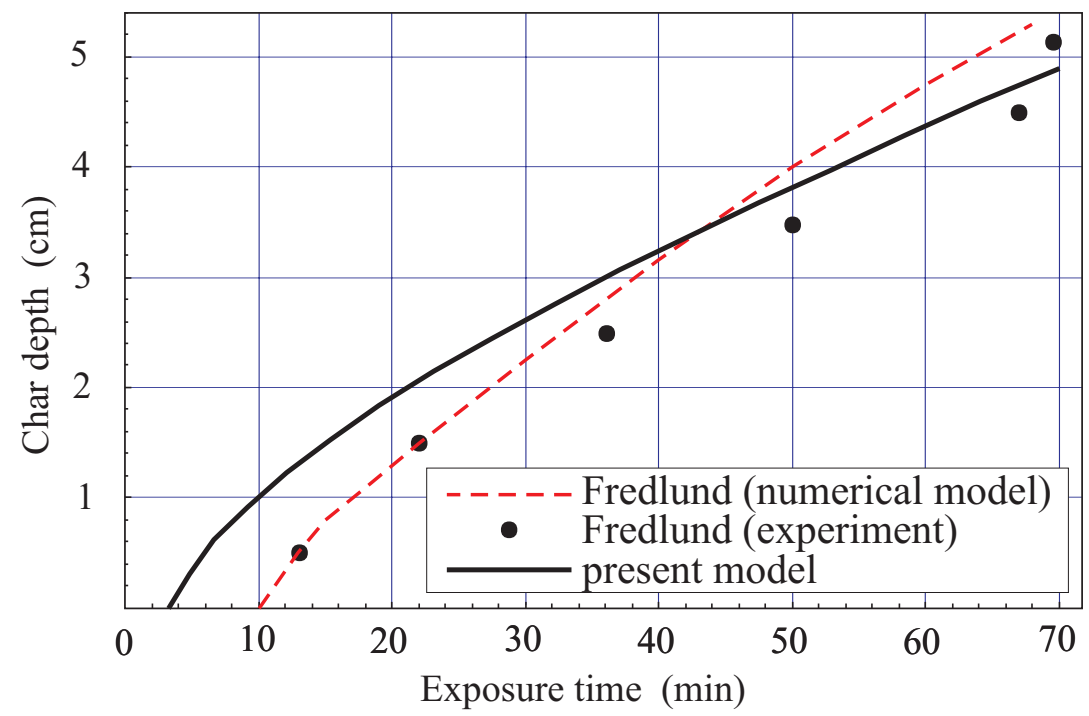

Figure 2. Comparison of experimental and numerical results for penetration of the char layer as a function of time for spruce with initial moisture content of $14.5 \%$.

A comparison between the calculations and the experiment is based on measured and calculated temperature-dependent thermo-mechanical properties of timber and char given by Fredlund $[16,17]$. The numerical example deals with a specimen of spruce of initial moisture content of $14.5 \%$. The results are also compared to the numerical model proposed by Fredlund [16, 17]. Fig. 2 shows a comparison of the penetration/formation of the char layer as a function of fire exposure time. In the Fredlund's calculations, the char front has been defined as the point at which density has dropped to $300 \mathrm{~kg} / \mathrm{m}^{3}$, while in the present model, a formation of char is defined as the point at which temperature reaches $300^{\circ} \mathrm{C}$. As it can be seen from Fig. 2, there is a very good agreement between measured and calculated results. This allows us to conclude, that the 
proposed mathematical model is generally appropriate for the prediction of charring behaviour of timber beams exposed to fire.

\subsection{Fire resistance of a two-layer timber composite beam exposed simultane-} ously to static loading and fire

In the following example, the mathematical model for a thermomechanical analysis of timber composite beams is used to determine the fire resistance of two-layer timber composite beam when simultaneously exposed to static loading and fire. A two-layer composite timber beam subjected to uniformly distributed static load, $p_{Z}$, and fire from three sides is considered. The descriptive geometric, material, and loading data are given in Fig. 3.

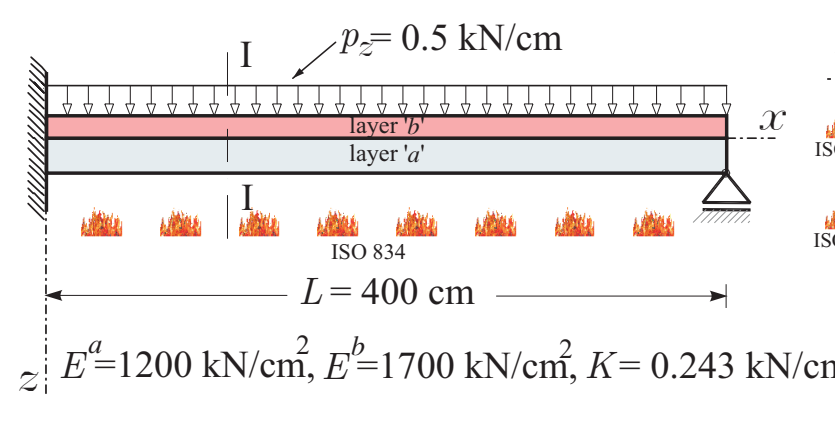

\section{Section I-I:}

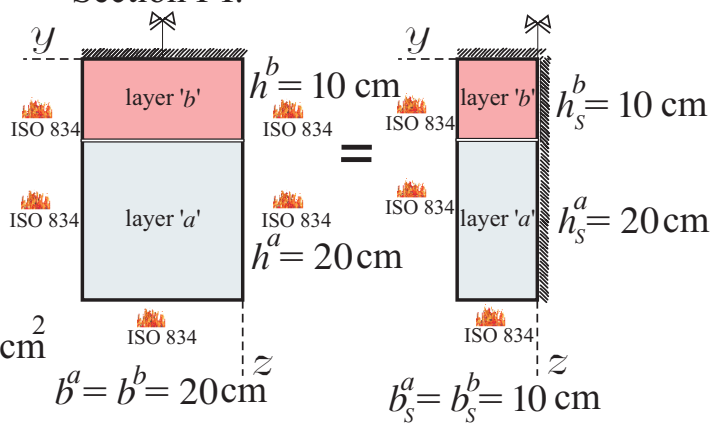

Figure 3. The descriptive geometric, material, and loading data of a two-layer timber composite beam.

It is further assumed, that heat and moisture transfer in the longitudinal direction is sufficiently small compared to the heat and moisture transfer across the cross-section and can be neglected. Consequently, the heat and moisture transfer problem over a typical cross-section governed by 2D Luikov equations (1)-(2) is solved. In this case, the temperature and moisture content distribution and the formation of a char layer in a two-layer timber composite beam exposed to standard fire conditions from three sides is considered. The upper 
surface of the timber beam is thermally isolated. Due to the symmetry of the cross-section and material and loading parameters, only one half of the cross-section is considered (see Fig. 3).

Since material properties at elevated temperatures are difficult to obtain, constant material properties of timber and char are used. The data for this case is as follows

$$
\begin{aligned}
& T_{0}=20^{\circ} \mathrm{C}, W_{0}=13^{\circ} \mathrm{M}, W_{A}=4^{\circ} \mathrm{M}, \rho_{\mathrm{w}}^{a}=370 \mathrm{~kg} / \mathrm{m}^{3}, \rho_{\mathrm{c}}^{a}=110 \mathrm{~kg} / \mathrm{m}^{3}, \varepsilon=0.3 \\
& \rho_{\mathrm{w}}^{b}=590 \mathrm{~kg} / \mathrm{m}^{3}, \rho_{\mathrm{c}}^{b}=180 \mathrm{~kg} / \mathrm{m}^{3}, k_{\mathrm{w}}^{a}=0.12 \mathrm{~W} /(\mathrm{mK}), k_{\mathrm{c}}^{a}=0.15 \mathrm{~W} /(\mathrm{mK}), \\
& k_{\mathrm{w}}^{b}=0.20 \mathrm{~W} /(\mathrm{mK}), k_{\mathrm{c}}^{b}=0.18 \mathrm{~W} /(\mathrm{mK}), D_{M}^{a}=D_{M}^{b}=2.2 \cdot 10^{-8} \mathrm{~kg} /\left(\mathrm{ms}^{\circ} \mathrm{M}\right), \\
& h_{L V}^{a}=h_{L V}^{b}=2500 \mathrm{~kJ} / \mathrm{kg}, h_{c}^{a}=h_{c}^{b}=22.5 \mathrm{~W} /\left(\mathrm{m}^{2} \mathrm{~K}\right), c_{p, \mathrm{w}}^{a}=1530 \mathrm{~J} /(\mathrm{kgK}), \\
& c_{p, \mathrm{c}}^{a}=1050 \mathrm{~J} /(\mathrm{kgK}), c_{p, \mathrm{w}}^{b}=2500 \mathrm{~J} /(\mathrm{kgK}), c_{p, \mathrm{c}}^{b}=1400 \mathrm{~J} /(\mathrm{kgK}), \gamma=0, \\
& c_{m}^{a}=c_{m}^{b}=0.01 \mathrm{~kg} /\left(\mathrm{kg}^{\circ} \mathrm{M}\right), \delta^{a}=\delta^{b}=2.0^{\circ} \mathrm{M} / \mathrm{K}, h_{m, \mathrm{w}}^{a}=h_{m, \mathrm{c}}^{a}=2.5 \cdot 10^{-6} \mathrm{~kg} /\left(\mathrm{m}^{2} \mathrm{~s}^{\circ} \mathrm{M}\right), \\
& h_{m, \mathrm{w}}^{b}=h_{m, \mathrm{c}}^{b}=0 \mathrm{~kg} /\left(\mathrm{m}^{2} \mathrm{~s}^{\circ} \mathrm{M}\right), h_{\mathrm{c}, \text { contact }}=1000 \mathrm{~W} /\left(\mathrm{m}^{2} \mathrm{~K}\right), h_{\mathrm{m}, \mathrm{contact}}=1000 \mathrm{~kg} /\left(\mathrm{m}^{2} \mathrm{~s}^{\circ} \mathrm{M}\right) .
\end{aligned}
$$

The distributions of temperature and the formation of char at times 1,5,10, 20, 30, 40, 50, and 60 minutes after the exposure are depicted in Figs. 4 and 5.

The boundary between the timber and the char is defined as a temperature isotherm of $300^{\circ} \mathrm{C}$. It can be seen, that temperature gradients are the highest at the boundary between the timber and the char. Charring is the fastest at the beginning and due to the material properties of the char gradually decrease with time. Since corners are subjected to heat and moisture transfer from two directions, charring is faster at corners. Due to higher density and specific heat in layer $b$, the charring in layer $b$ is slower than in the layer $a$. From Figs. 4 and 5 we can see, that charring stars at the lower corner. As a result, a rounding effect occurs and shortly after the ignition the remaining load bearing cross-section is no longer rectangular. The calculated temperature and moisture distributions 

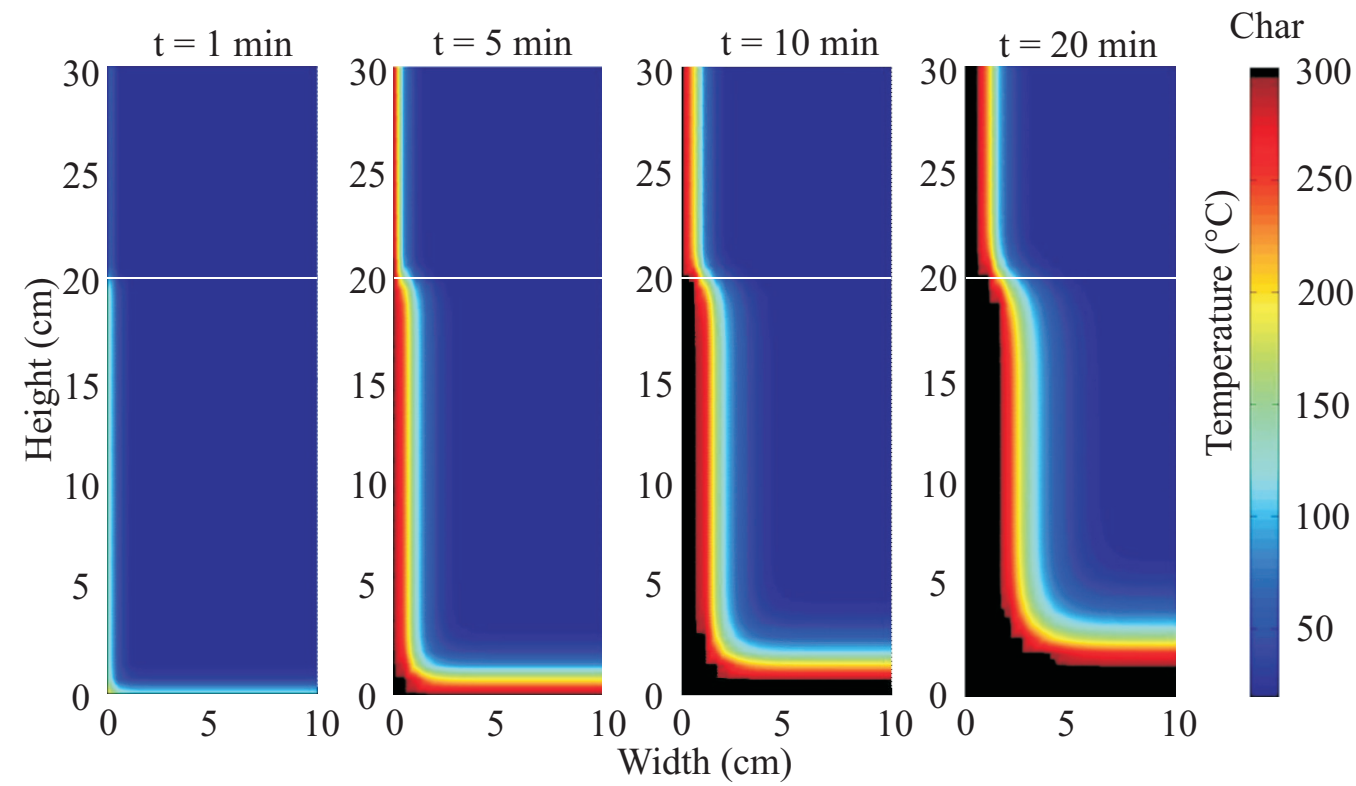

Figure 4. Temperature distribution in the cross-section of a two-layer timber composite beam and the transformation of timber into char at 1,5,10, and 20 minutes.

and the formation of the char will be used in the mechanical response analysis of two-layer timber composite beam with interlayer slip when simultaneously exposed to static loading and fire.

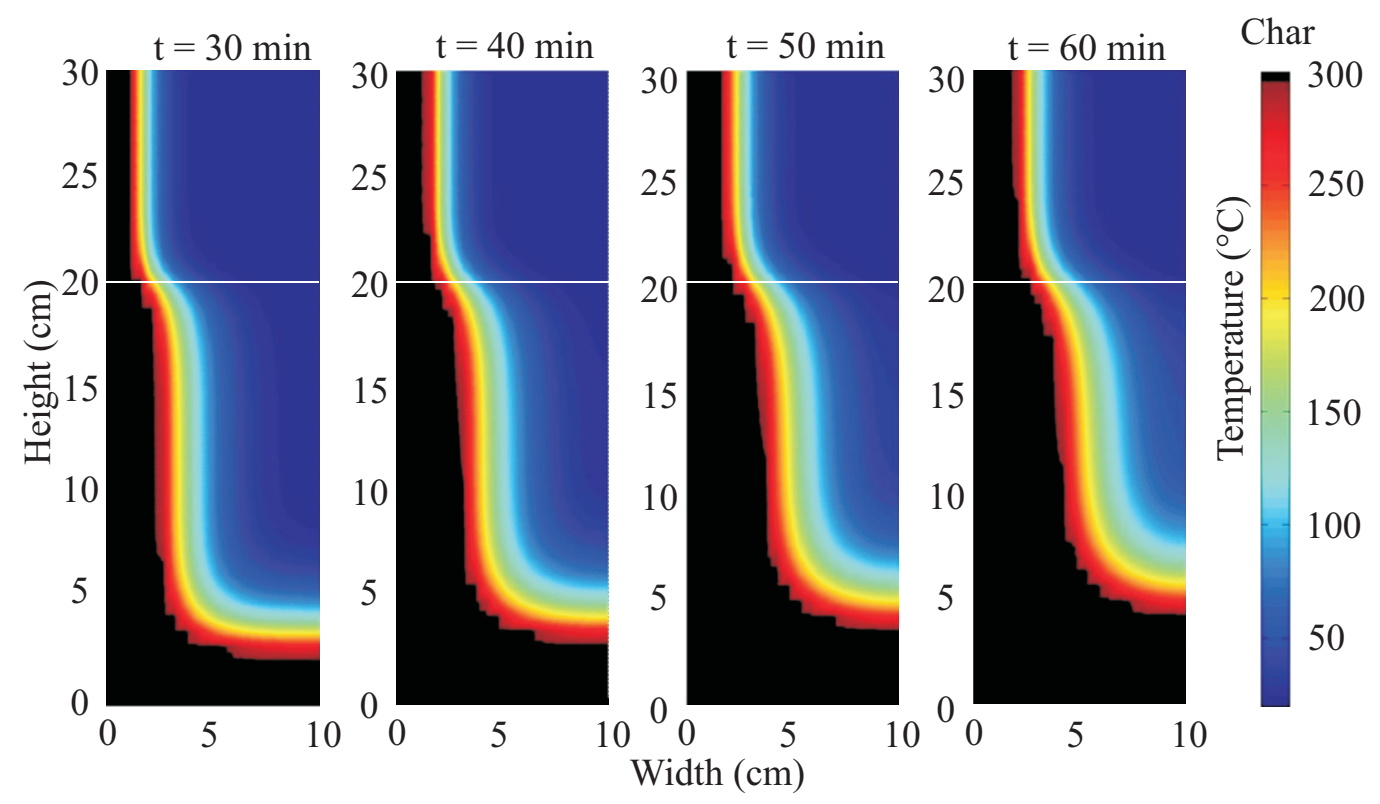

Figure 5. Temperature distribution in the cross-section of a two-layer timber composite beam and the transformation of timber into char at 30,40, 50, and 60 minutes. 
When temperature and moisture distributions are known, they can be used in the mechanical response analysis of the two-layer timber composite beam when simultaneously exposed to static loading and fire. To adequately model the behaviour of composite structures, the material properties at elevated temperatures and fire conditions must be accurately defined. The material properties are affected by temperature, moisture content, specific density, and grain orientation. In this paper, only temperature dependence is taken into account. In order to determine the fire behaviour of load-bearing two-layer composite beams, it is necessary to establish the mechanical properties of the material at elevated temperatures.

For timber, the mechanical properties include strength and stiffness. These properties are affected by temperature, moisture content, rate of charring and grain orientation. As the temperature of timber increases, its strength and stiffness decrease. In general, at charring temperature of $300^{\circ} \mathrm{C}$ it is assumed that the strength and stiffness drop to zero.

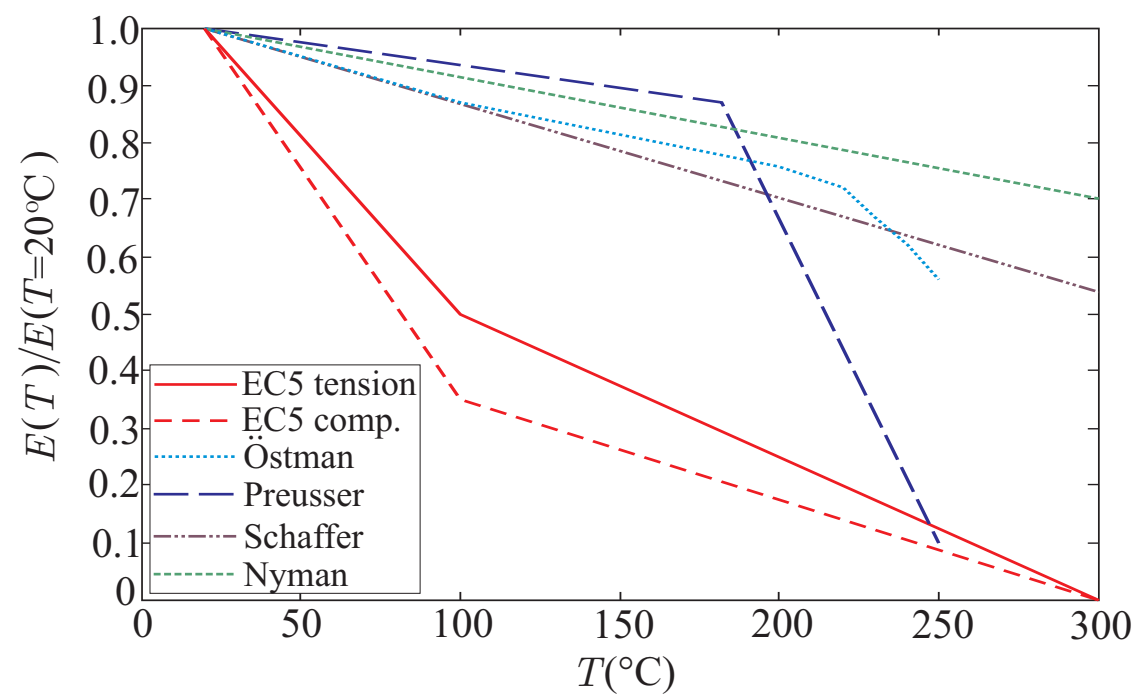

Figure 6. Reduced modulus of elasticity $E$ ) of timber at elevated temperatures proposed by various researchers, see [40]. 
Fig. 6 shows the modulus of elasticity parallel-to-grain, $E$, versus temperature as reported by different researchers, see e.g. [40]. These mechanical properties have been used in the following mechanical response analysis of the two-layer composite beam when simultaneously exposed to static loading and fire. In the mechanical response analysis, the derived strain-based finite elements are employed and the geometric strain increment is assumed to be the sum of increments of elastic and temperature strains. The two-layer timber composite beam is modelled by ten finite elements described previously, for which the strains are interpolated by the Lagrangian polynomials of the eight order. The time interval $t \in[0,60] \mathrm{min}$ is divided into 60 time steps $\Delta t=1 \mathrm{~min}$. Fig. 7 shows maximal vertical deflection calculated for different mechanical properties proposed by various researchers. Static vertical deflection $w_{\mathrm{S}}=$ $2.993 \mathrm{~cm}$, which is constant with time is shown also. As shown in the Fig. 7, the discrepancies of the maximal vertical deflections are relatively small in the first minutes, but later a discrepancy between these deflections increases considerably.

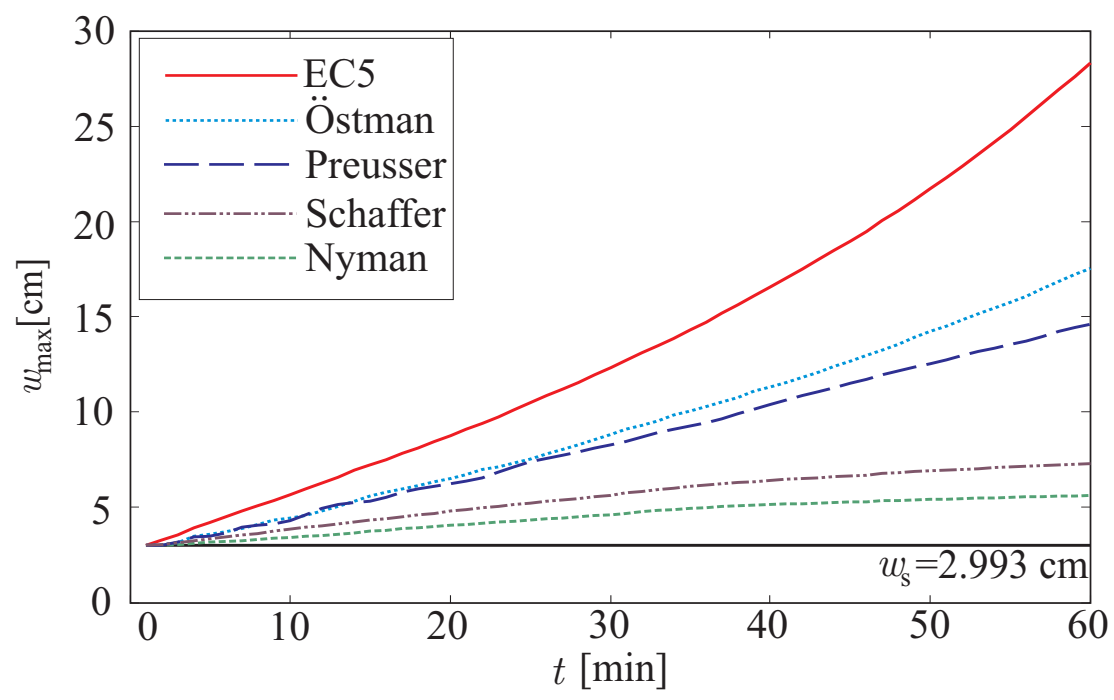

Figure 7. Maximal vertical deflection versus time for the two-layer timber composite beam calculated by different material models. 
The highest values of the maximal vertical deflections are obtained by the use of EC 5 regulations [37]. A structural limit state is usually defined as the moment when the stress caused by the applied load exceeds the physical resistance of the beam, or when the span/deflection ratio drops below a certain value (usually $\frac{L}{w_{\max }} \approx 30$, see, e.g., [38]). In the latter case, it is said that the deflection limit state of the beam is reached. The latter case is also used as a limit state in the present paper. As a result, a critical vertical deflection is $w_{\text {cr }} \approx 13 \mathrm{~cm}$. In this case, the actual times to failure are: EC $5(t \approx 30 \mathrm{~min})$; Östman $(t \approx 47 \mathrm{~min})$; Preusser $(t \approx 56 \mathrm{~min})$.

Figs. 8 and 9 show distributions of interlayer slips and vertical deflections along the two-layer composite beam at $t=60 \mathrm{~min}$, and calculated by different material models.

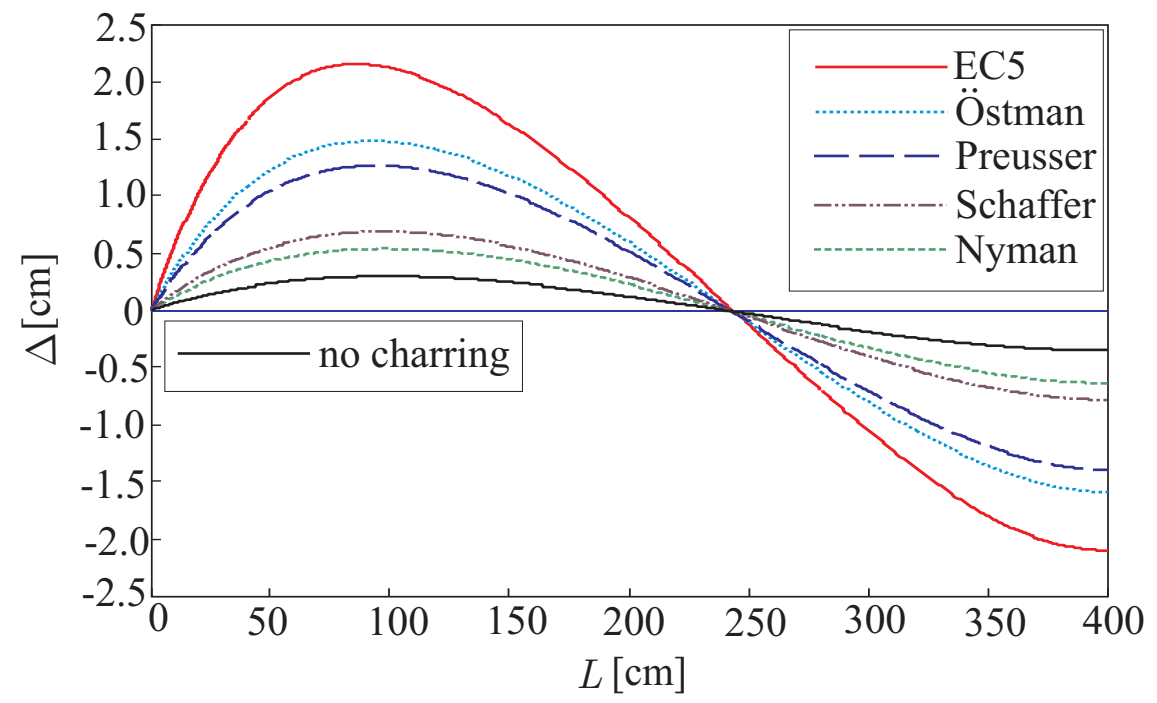

Figure 8. Distributions of interlayer slip along the two-layer beam at $t=60 \mathrm{~min}$, calculated by different material models. 


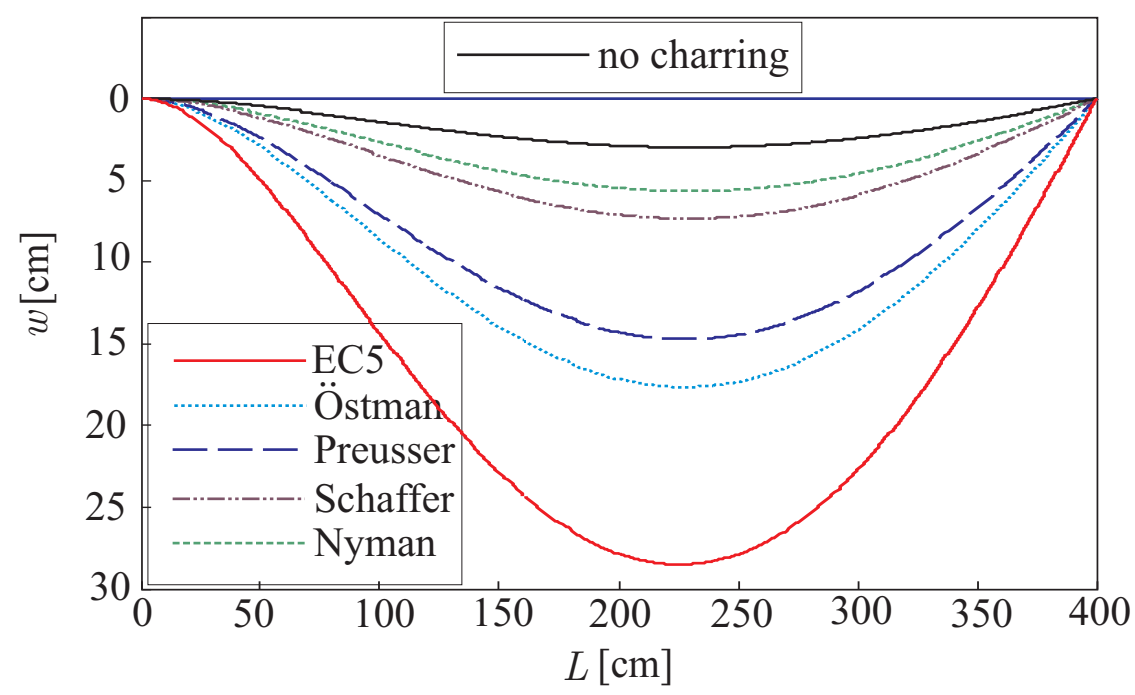

Figure 9. Distributions of vertical deflection along the two-layer beam at $t=60$ min, calculated by different material models.

Similarly, Figs. 10 and 11 show the distributions of interlayer slips and vertical deflections along the two-layer composite beams calculated at times $t=0,10,20,30,40,50$, and 60 minutes for EC5 [37] material model.

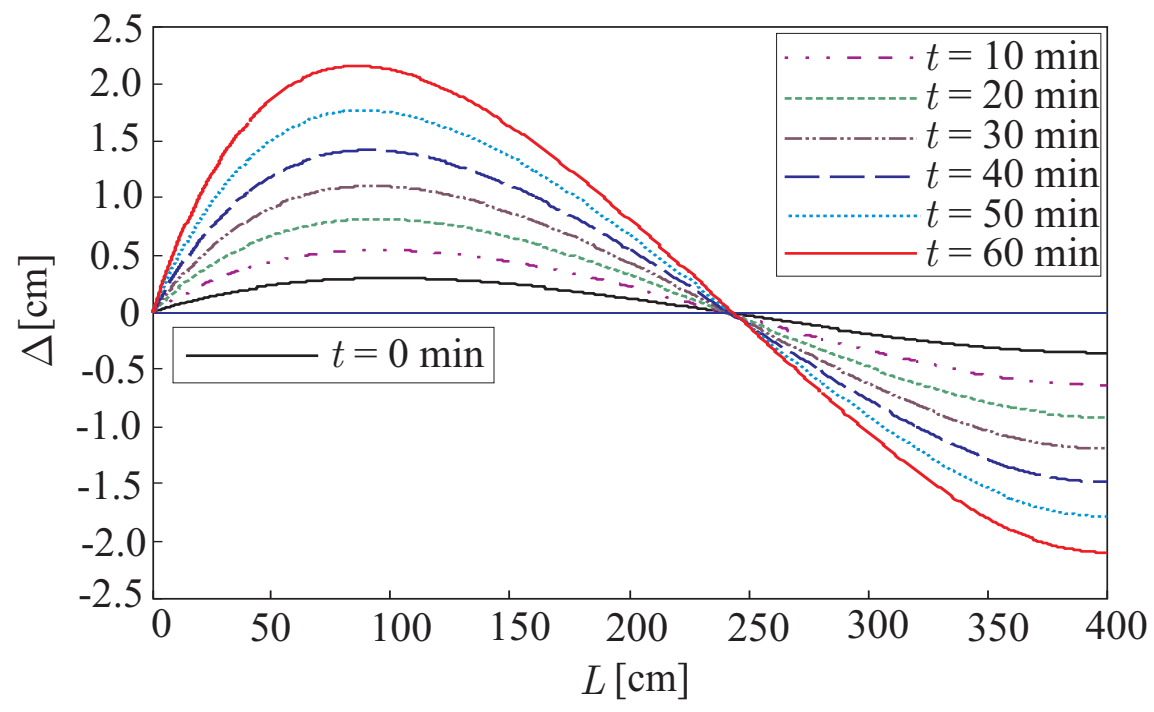

Figure 10. Distributions of the interlayer slip along the two-layer beam at times $t=0,10,20,30,40,50$, and 60 minutes for EC5 [37] material model. 


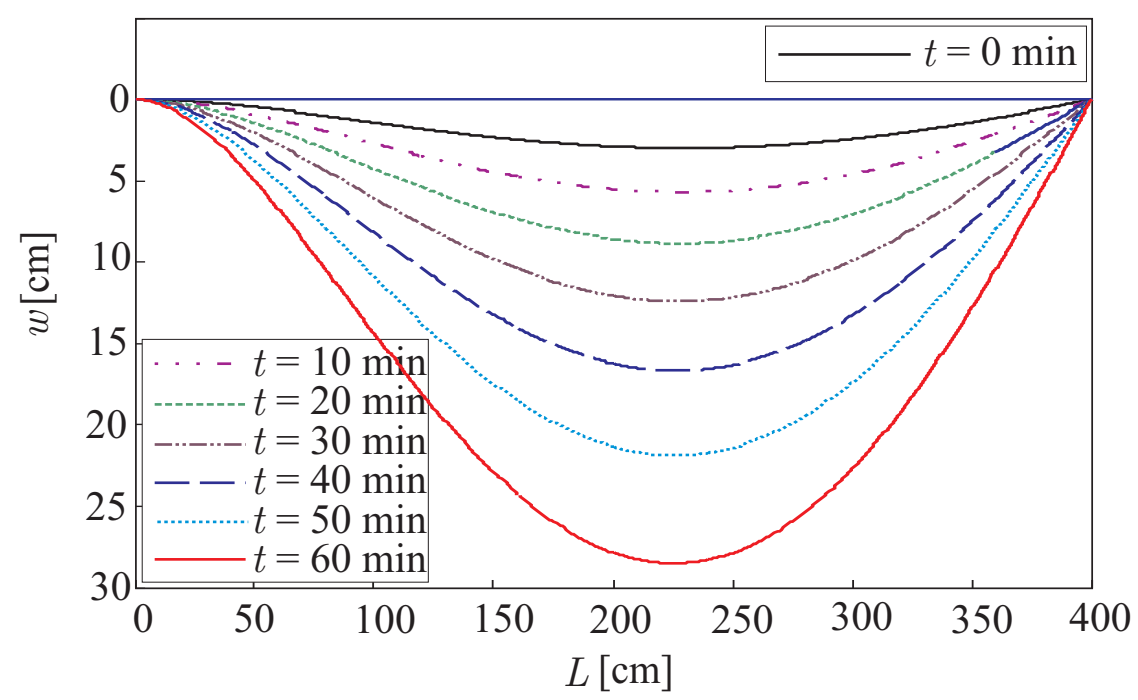

Figure 11. Distributions of the vertical deflection along the two-layer beam at times $t=0,10,20,30,40,50$, and 60 minutes for EC5 [37] material model.

In order to estimate the effect of contact stiffness $K$ on deflections and interlayer slip of two-layer composite beam Figs. 12 and 13 are shown. The maximum deflection in the case of weak connection is as high as 5 times higher than in the case of absolutelly stiff conection. Similar effect can be observed when interlayer slips are compared.

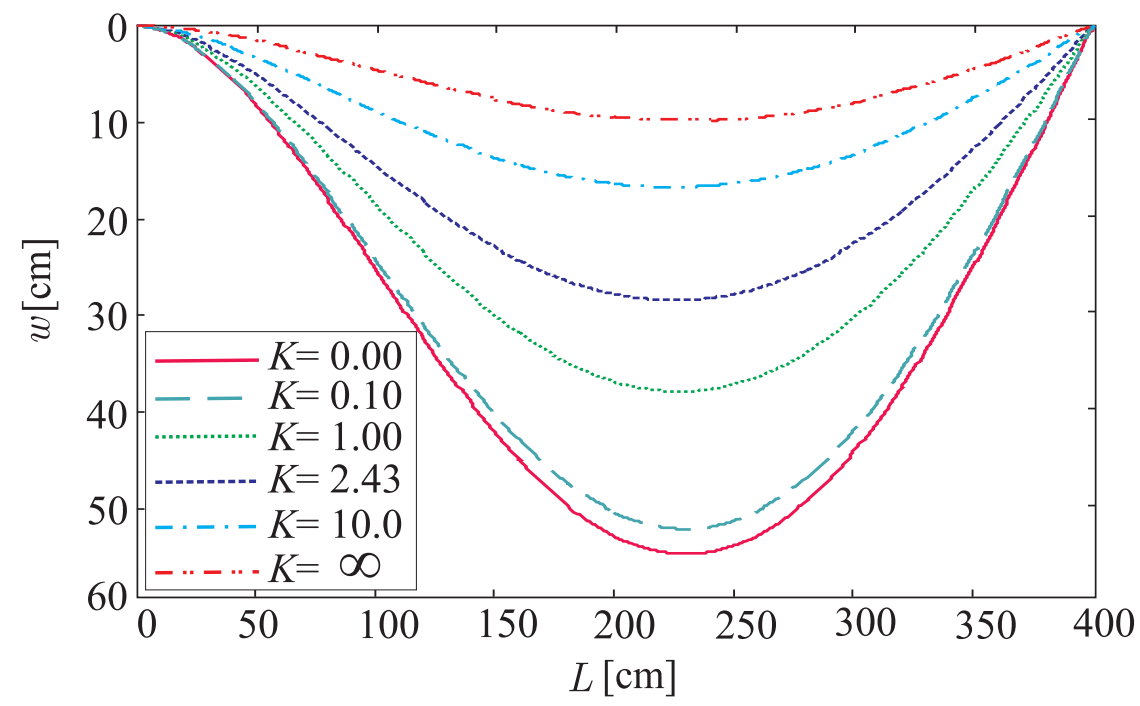

Figure 12. Distributions of the vertical deflection along the two-layer beam for different interlayer contact stiffness $K$. 


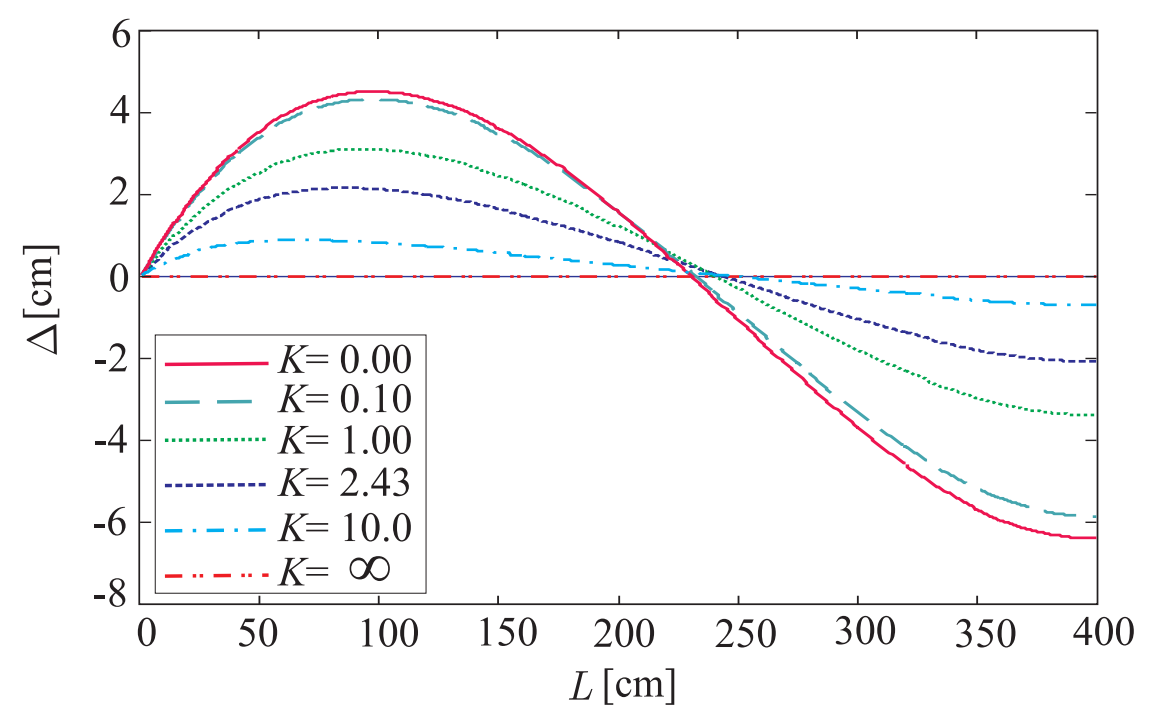

Figure 13. Distributions of the interlayer slip along the two-layer beam for different contact stiffness $K$.

\section{Conclusions}

A mathematical model for thermomechanical problem has been proposed and its numerical solution has been found for the analysis of timber composite beams with partial interaction between the layers when simultaneously exposed to static loading and fire. The study has been carried out for evaluating the charring depths of solid timber beams and comparing the results to those published in the literature. Furthermore, the mathematical model has also been used to determine a fire resistance of a two-layer timber composite beam subjected simultaneously to uniform static loading and standard fire conditions. Particular emphasis has been given to the influence of temperature dependent mechanical properties of timber on its fire resistance. For this purpose, vertical deflections and interlayer slips have been calculated for different material models which have been proposed in the literature. Based on the results, the following important conclusions can be drawn: 
(1) The present mathematical model for thermomechanical analysis of timber beams is general and relatively easy to comprehend. Its applicability for the stress-strain analysis of the composite beams subjected to mechanical and fire loads has been clearly illustrated by the numerical examples.

(2) The comparison of the proposed charring model with the empirical charring models from the literature shows, that models proposed in [36] and by Schaffer [27] differ considerably. The Lawson's and Schaffer's models differ slightly at the beginning, but are virtually equal at 60 minutes. Similarly, the model proposed by Eurocode 5 [37], White's and Nordheim's model [28], and the model proposed in this paper differ considerably in the first 15 minutes, but later show similar results.

(3) A good agreement is obtained between the theoretical predictions of the one-dimensional charring depths in timber beams and the results obtained from experiments conducted by Fredlund [16, 17].

(4) The temperature gradients are the highest at the boundary between the timber and the char. Charring is the fastest at the beginning and due to the material properties of the char gradually decreases with time. Since corners are subjected to heat and moisture transfer from two directions, charring is faster at these corners. The charring always starts at the corner. As a result, a rounding effect occurs and shortly after the ignition the remaining load bearing cross-section is no longer rectangular.

(5) Discrepancies of maximal vertical deflections in layered timber beams are relatively small in the first minutes, but later on the discrepancy between these deflections calculated by different material models differs considerably. The maximum values of the vertical deflections are obtained by the use of EC 5 regulations [37]. 
(6) If a structural limit state is defined as: $\frac{L}{w_{\max }} \approx 30$, see, e.g., [38], the critical vertical deflection in the above-mentioned numerical example is $w_{\mathrm{cr}} \approx 13 \mathrm{~cm}$. In this case, the actual times to failure are: EC $5(t \approx 30$ $\min )$; Östman $(t \approx 47 \mathrm{~min})$; Preusser $(t \approx 56 \mathrm{~min})$; showing great differnces between different well established temperature dependent material models.

\section{References}

[1] N.M. Newmark, C.P. Siest, C.P. Viest, Test and analysis of composite beams with incomplete interaction, in: Proceedings of the Society for Experimental Stress Analysis, 1, 75-92, 1951.

[2] J.R. Goodman, E.P. Popov, Layered beam systems with inter-layer slip, J. Struct. Div. ASCE, 94(11) (1968) 2535-2547.

[3] J.R. Goodman, E.P. Popov, Layered wood systems with inter-layer slip, Wood Science 1(3) (1969) 148-158.

[4] U.A. Girhammar, V.K.A. Gopu, Composite beam-columns with interlayer slip-exact analysis, J. Struct. Eng. ASCE 199(4) (1993) 1265-1282.

[5] N.A. Jasim, A.A.M. Ali, Deflections of composite beams with partial shear connection, Structural Engineer 74, Nos. 23 and 24, (1996).

[6] G. Ranzi, M.A. Bradford, B. Uy, A general method of analysis of composite beams with partial interaction, Steel and Composite Structures 3(3) (2003) 169-184.

[7] U.A. Girhammar, D. Pan, Dynamic analysis of composite members with interlayer slip, Journal of Solids and Structures 33(6) (1993) 797-823.

[8] A. Dall'Asta, Composite beams with weak shear connection, Finite Ele- 
ments in Analysis and Design 38 (2001) 5605-5624.

[9] A. Ayoub, A two-field mixed variational principle for partially connected composite beams, Finite Elements in Analysis and Design 37 (2001), 929959.

[10] A. Dall'Asta, A. Zona, Non-linear analysis of composite beams by a displacement approach, Computers and Structures 80 (2002) 2217-2228.

[11] A. Dall'Asta, A. Zona, Slip locking in finite elements for composite beams with deformable shear connection, Finite Elements in Analysis and Design 40 (2004) 1907-1930.

[12] B. Čas, M. Saje, I. Planinc, Nonlinear finite element analysis of composite planar frames with inter-layer slip, Computers and Structures 82 (2004) $1901-1912$.

[13] B. Čas, S. Bratina, M. Saje, I. Planinc, Non-linear analysis of composite steel-concrete beams with incomplete interaction", Steel and Composite Structures 4(6) (2004) 489-507.

[14] S. Schnabl, M. Saje, G. Turk, I. Planinc, Analytical solution of two-layer beam taking into account interlayer slip and shear deformation, Journal of Structural Engineering ASCE 133(6) (2007) 886-894.

[15] I. Planinc, S. Schnabl, M. Saje, J. Lopatič, B. Caas, Numerical and experimental analysis of timber composite beams with interlayer slip, Engineering Structures 30 (2008) 2959-2969.

[16] B. Fredlund, A model for heat and mass transfer in timber structures during fire. A theoretical, numerical and experimental study, Report LUTVDG/(TVBB-1033), Department of fire safety engineering, Lund institute of science and Technology, Sweden, 1988.

[17] B. Fredlund, Modelling of heat and mass transfer in wood structures during fire, Fire Safety Journal 20 (1993) 39-69. 
[18] A. Frangi, C. Erchinger, M. Fontana, Charring model for timber frame floor assemblies with void cavities, Fire Safety Journal (2008) doi:10.1016/j.firesaf.2007.12.009

[19] A. Frangi, M. Knobloch, M. Fontana, Fire design of timber slabs made of hollow core elements, Engineering Structures (2008) doi:10.1016/j.engstruct.2008.08.002

[20] V. Babrauskas, Charring rate of wood as a tool for fire investigations, Fire Safety Journal 40 (2005) 528-554.

[21] M. Delichatsios, B. Paroz, A. Bhargava, Flammability properties for charring materials, Fire Safety Journal 38 (2003) 219-228.

[22] M.J. Spearpoint, J.G.Quintiere, Predicting the burning of wood using an integral model. Combust Flame 123 (2000) 308-324

[23] D.K. Shen, M.X. Fang, Z.Y. Luo, K.F Cen, Modeling pyrolysis of wet wood under external heat flux, Fire Safety Journal 42 (2007) 210-217

[24] M.L. Janssens, Modeling of the thermal degradation of structural wood members exposed to fire, Fire Mater 28 (2004) 199-207.

[25] S.A. Young, P. Clancy, Structural modelling of light-timber framed walls in fire, Fire Safety Journal 36 (2001) 241-268

[26] C. Di Blasi, The state of the art of transport models for charring solid degradation, Polymer International 49 (2000) 1133-1146.

[27] E.L. Schaffer, Charring rate of selected woods-transverse to grain, Research paper FPL-69, USDA Forest Product Laboratory, Madison, Wisconsin, USA, 1967

[28] R.H. White and E.V. Nordheim, Charring rate of wood for ASTM E 119 exposure, Fire Technology 28(1) (1992) 5-30.

[29] D.I. Lawson, C.T. Webster and L.A. Ashton, Fire endurance of timber beams and floors, Journal of Structural Engineering 30(2) (1952) 27-34. 
[30] A.V. Luikov, Heat and Mass Transfer in Capillary-porous Bodies, Pergamon Press, Oxford, 1966.

[31] E. Reissner, On one-dimensional finite-strain beam theory: The plane problem, Journal of Applied Mechanics and Physics ZAMP 23 (1972) $795-804$.

[32] B. Vratanar, M. Saje, A consistent equilibrium in a cross-section of an elastic-plastic beam, Journal of Solids and Structures 36 (1999) 311-337.

[33] I. Planinc, M. Saje, B. Čas, On the local stability condition in the planar beam finite element, Structural Engineering and Mechanics 12(5) (2001) $507-526$.

[34] S. Schnabl, M. Saje, G. Turk, and I. Planinc, Locking-free two-layer Timoshenko beam element with interlayer slip, Finite Elements in Analysis and Design 43 (2007) 705-714.

[35] ISO 834, Fire-resistance test - Elements of building construction-Part 1. General requirements. ISO 834-1, International organization for standardization, Geneva, Switzerland, 1999.

[36] AS 1720.4., Timber structures - Fire resistance of structural timber members, 1990

[37] EN 1995-1-2, Eurocode 5, Design of timber structures Part 1-2: GeneralStructural fire design, 2004.

[38] N. Benichou, Structural response modelling of wood-joist floor assemblies exposed to fires, Interflam 2004 Conference, Edinburg, Scotland: 233-244, 2004 .

[39] J.N. Reddy, Applied functional analysis and variational methods in engineering, McGraw-Hill Book Company, Singapore, 1986.

[40] A.H. Buchanan, Fire performance of timber construction, Progress in Structural Engineering and Materials 2(3) (2000) 278-289. 


\section{Figure Captions:}

- Figure 1: Comparison of different empirical charring models with the present one.

- Figure 2: Comparison of experimental and numerical results for penetration of the char layer as a function of time for spruce with initial moisture content of $14.5 \%$.

- Figure 3: The descriptive geometric, material, and loading data of a twolayer timber composite beam.

- Figure 4: Temperature distribution in the cross-section of a two-layer timber composite beam and the transformation of timber into char at 1,5,10, and 20 minutes.

- Figure 5: Temperature distribution in the cross-section of a two-layer timber composite beam and the transformation of timber into char at 30, 40, 50, and 60 minutes.

- Figure 6: Reduced modulus of elasticity $E$ ) of timber at elevated temperatures proposed by various researchers, see [40].

- Figure 7: Maximal vertical deflection versus time for the two-layer timber composite beam calculated by different material models.

- Figure 8: Distributions of interlayer slip along the two-layer beam at $t=60$ min, calculated by different material models.

- Figure 9: Distributions of vertical deflection along the two-layer beam at $t=60 \mathrm{~min}$, calculated by different material models.

- Figure 10: Distributions of the interlayer slip along the two-layer beam at times $t=0,10,20,30,40,50$, and 60 minutes for EC5 [37] material model.

- Figure 11: Distributions of the vertical deflection along the two-layer beam at times $t=0,10,20,30,40,50$, and 60 minutes for EC5 [37] material model. 
- Figure 13: Distributions of the vertical deflection along the two-layer beam for different interlayer contact stiffness $K$.

- Figure 14: Distributions of the interlayer slip along the two-layer beam for different contact stiffness $K$. 